\title{
Evaluation of Stress Intensity Factor of Silicon Nitride with Bridge Indentation Crack by Caustic Method
}

\author{
Toshio OGASAWARA, Tohru AKIBA, Keizo OTANI, Yoshio AKIMUNE and Koji SHIMIZU* \\ Material Research Laboratory, Nissan Research Center, Nissan Motor Co., Ltd., 1, Natsushima-cho, Yokosuka-shi 237 \\ *Department of Mechanical Engineering, Faculty of Engineering, Kanto Gakuin University, \\ 4834, Mutsuura, Kanazawa-ku, Yokohama-shi 236
}

\section{BI 予き裂を有する窒化ケイ素の Caustic 法による応力拡大係数の評価 小笠原俊夫・䅖場 亨・尾谷敬造・秋宗淑雄・清水紘治* \\ 日産自動車(株)総合研究所材料研究所, 237 横須賀市夏島町 1 *関東学院大学工学部機械工学科, 236 横浜市金沢区六浦 4834}

[Received February 17, 1992; Accepted April 23, 1992]

\begin{abstract}
The caustic method is an optical technique for determining the dynamic stress intensity factor of metals and plastics. In this study, the application of the caustic method to ceramics was investigated, and a technique is proposed here for determining the static stress intensity factor from a fine caustic image of a ceramic specimen. The degree of deviation of parallelism and surface roughness of a specimen are important factors in obtaining a clear caustic image of ceramics. A reliable method for measuring the diameter of a caustic by image processing was proved to be effective in this experiment. The stress intensity factor of $\mathrm{Si}_{3} \mathrm{~N}_{4}$ with a $\mathrm{BI}$ (bridge indentation) crack was evaluated, and the residual stress intensity factor caused by a Vickers indentation for a starter crack was examined using this method.
\end{abstract}

Key-words : Caustic method, Stress intensity factor, Silicon nitride, Image processing, Bridge indentation method

\section{Introduction}

The caustic method is an optical tool for measuring the stress intensity factor of plastics and metals. ${ }^{1-5)}$ Using this method, the stress intensity factor of notched or pre-cracked specimen is measured directly without touching the specimens. Therefore, the caustic method can be applied to determine dynamic fracture toughness using a high-speed camera.

With this method, the stress intensity factor $\left(K_{\mathrm{I}}\right)$ is determined by measuring the deformation of the specimen surface surrounding a crack tip. The surface deformation of ceramics is very small because of their high Young's modulus and low fracture toughness. As a result, few applications of the caustic method to ceramic materials have been reported.4),6)

Despite the difficulties of applying this method to ceramics, the present authors thought that it might be possible to use this approach to determine the stress intensity factor of ceramic materials by improving the specimen machining process, optimizing the optical setup conditions and using an image processing technique to obtain a fine caustic image. In this study, the application of the caustic method to ceramics was investigated, and the stress intensity factor of $\mathrm{Si}_{3} \mathrm{~N}_{4}$ with a bridge indentation crack was evaluated.

2. Basic principle of caustic method

Figure 1 shows the basic principle of the caustic method. When a pre-cracked or notched specimen under a certain load is illuminated by a divergent light beam, deformation of the specimen surface surrounding the crack tip caused the optical path length to change. Thus, the area surrounding the crack tip acts as a concave mirror and the light rays are reflected outwards. As a consequence, a shadow area and a caustic (bright ring around the shadow area) are observed on an image plane (a screen) at a distance $Z_{0}$ from the specimen. The diameter of the caustic is related to the stress intensity factor at the crack tip under plane stress condition as indicated in the following Eq. (1).

$$
\left\{\begin{array}{l}
K_{\text {Icaustic }}=1.671\left(\frac{E}{Z_{0} v B}\right) \lambda^{-3 / 2}\left(\frac{D_{\mathrm{a}}}{3.17}\right)^{5 / 2} \\
D_{\mathrm{a}}=3.17 \lambda r_{0}
\end{array}\right.
$$

and

$$
\lambda=\frac{Z_{0}-Z_{\mathrm{i}}}{Z_{\mathrm{i}}}
$$

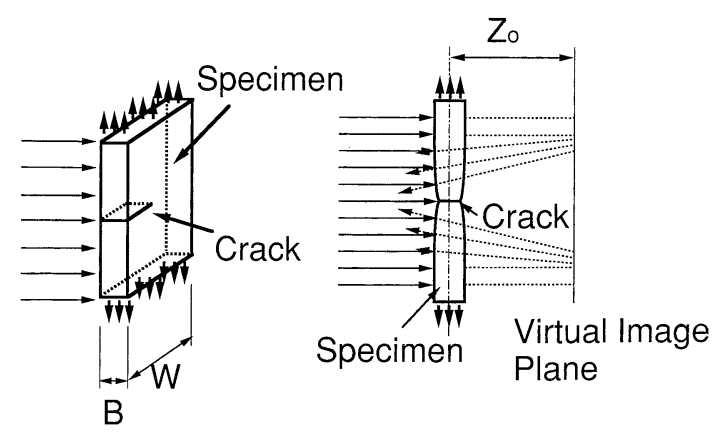

Fig. 1. Basic principle of caustic method. 
where $D_{\mathrm{a}}$ is the diameter of the caustic, $\lambda$ is the magnification factor of the optical system, $Z_{\mathrm{i}}$ is the distance from the specimen to the focus, $K_{\text {Icaustic }}$ is the stress intensity factor, $r_{0}$ is the initial curve, and $E$ and $v$ are the Young's modulus and Poisson's ratio. The caustic is given by the deformation of the specimen surface at the distance $r_{0}$ from the crack tip.

Determining the stress intensity factor of ceramics using the caustic method is a difficult task as described earlier. To obtain a clear caustic image, it is necessary to optimize the optical setup conditions. The diameter of the caustic is influenced by the initial curve $r_{0}$, which varies with the applied stress intensity factor $K_{\text {Ia }}$, the distance from the specimen to the screen $Z_{0}$, and the magnification factor $\lambda$ of the optical system.

\section{Experimental procedure}

A pressureless sintered silicon nitride ceramic was used in the experiment. The mechanical properties of the material are listed in Table 1. Specimens measured $7.5 \mathrm{~mm}$ in width $(W)$ and $6 \mathrm{~mm}$ in thickness $(B)$, and three-point bending tests were performed with a span of $S=30 \mathrm{~mm}$ and $S / W=4$. It should be noticed that the specimen width in the experiment was too wide to calculate the stress intensity factor using Eq. (1), because Eq. (1) is based on plane stress condition.

A degree of deviation of parallelism and surface roughness of a specimen are important factors in obtaining a clear caustic image. Unless these parameters are optimized, it is impossible to obtain the clear caustic image accurately on account of fringe patterns. According to the results of preliminary experiments, the deviation of parallelism (JISB0021) and the surface roughness (JIS-B0601) should be less than $0.01 \mathrm{~mm}$ and $R_{\mathrm{a}}=0.02 \mu \mathrm{m}$ respectively. All of the specimens were pre-cracked by the Bridge Indentation (BI) method. This method is a technique for propagating a starter crack, such as an indentation one, to a straight through-thickness crack. ${ }^{7)}$ In this experiment, a Vickers indentation was used as the starter crack generator and the indentation load was $196 \mathrm{~N}$.

The optical setup used in the experiment is shown in Fig. 2. A He-Ne laser was used as the light source. The laser beam was expanded and collimated by a laser collimator and focused by a convex lens $(f=500 \mathrm{~mm})$. As caustic images of ceramics are not

Table 1. Mechanical properties of silicon nitride ceramic.

\begin{tabular}{|l|c|}
\hline Density & $3.2 \mathrm{~g} / \mathrm{cm}^{3}$ \\
\hline Young's Modulus $^{*}$ & $265 \mathrm{GPa}$ \\
\hline Fracture Toughness & $5.0 \mathrm{MPaVm}$ \\
\hline Flexural Strength & $695 \mathrm{MPa}$ \\
\hline \multicolumn{2}{|c|}{ "JIS-R1602 Resonant frequency method } \\
"NIS-R1607 SEPB method \\
"** JIS-R1601 4-point flexural strength
\end{tabular}

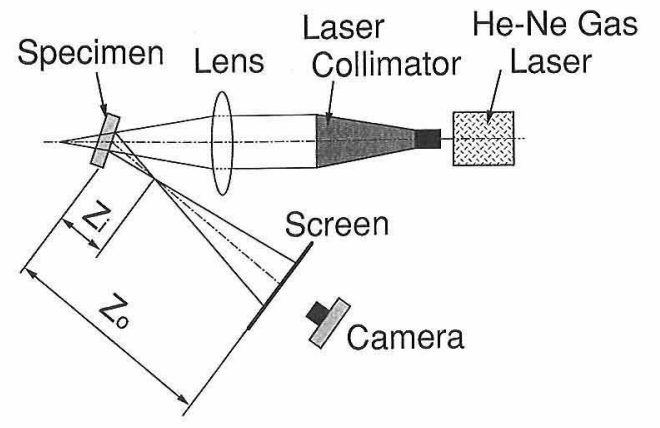

Fig. 2. Schematic diagram of experimental optical setup condition used with caustic method.

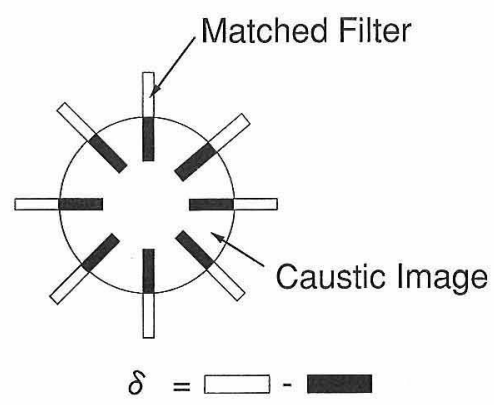

Fig. 3. Schematic diagram of matched filter setup for determining diameter and location of black circle.

always clear, it is necessary to have a reliable method of measuring the caustic diameter. In this experiment, an image processing technique was used to measure the diameter of caustic images. The diameter and location of the black circle were measured using matched filters as shown in Fig. 3. Eight rectangular matched filters were employed and the filter output was given by

$$
\begin{aligned}
\delta= & \Sigma(\text { intensity of pixels in white area }) \\
& -\Sigma(\text { intensity of pixels in black area })
\end{aligned}
$$

When the filter output $\delta$ is maximum value in the scanning area, the location and diameter of the caustic image were determined by this filter arrangement.

\section{Result and discussion}

The caustic images were not always clear as seen in Fig. 4. Consequently, the diameter of the caustic images was measured objectively using an image processing technique and the matched filter setup as shown in Fig. 3. This image processing technique was effective in determining the diameter of the images. The relations between the stress intensity factor evaluated with the caustic method $\left(K_{\text {Icaustic }}\right)$ and the applied stress intensity factor $\left(K_{\text {Ia }}\right)$ calculated with the applied load and the crack length are shown in Figs. 5(a) and (b).

The optical setup conditions were $Z_{\mathrm{i}}=435 \mathrm{~mm}$ and $Z_{0}=2065 \mathrm{~mm}$ for the results in Fig. 5 (a) and $Z_{\mathrm{i}}$ $=200 \mathrm{~mm}$ and $Z_{0}=2190 \mathrm{~mm}$ in Fig. 5 (b) respective- 

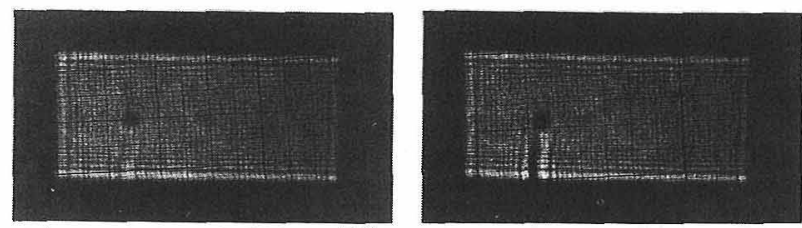

$\mathrm{KI}=1.0 \mathrm{MPa} \sqrt{\mathrm{m}}$

$\mathrm{KI}_{\mathrm{I}}=2.0 \mathrm{MPa} \sqrt{\mathrm{m}}$
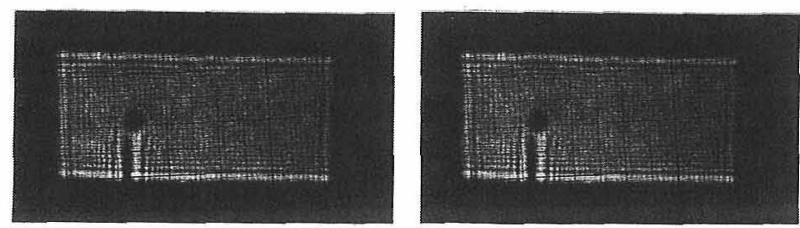

$\mathrm{KI}=3.6 \quad \mathrm{MPa} \sqrt{\mathrm{m}} \quad \mathrm{KI}=4.4 \quad \mathrm{MPa} \sqrt{\mathrm{m}}$

Fig. 4. Optical photograph of a caustic of $\mathrm{Si}_{3} \mathrm{~N}_{4}$. Optical setup conditions are $Z_{0}=2065 \mathrm{~mm}$ and $Z_{\mathrm{i}}=435 \mathrm{~mm}$.

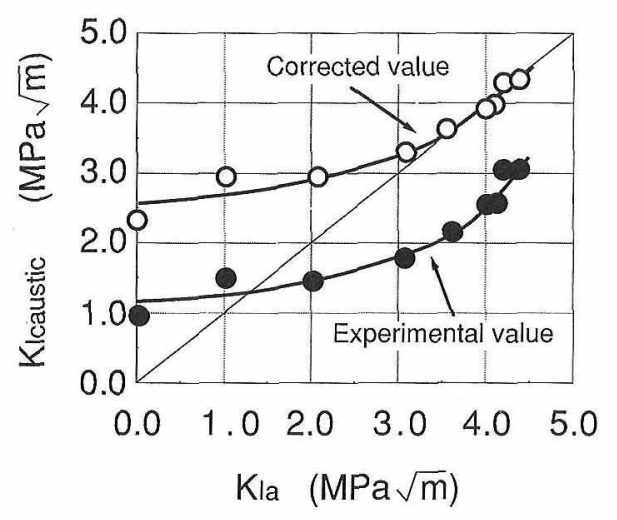

(a)

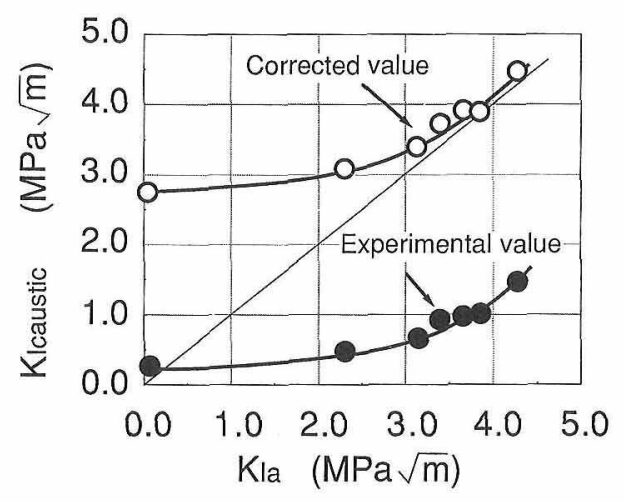

(b)

Fig. 5. Stress intensity factor $K_{\text {Icaustic }}$ determined by caustic method as a function of applied stress intensity factor $K_{\text {Ia }}$. Symbols $\bigcirc$ and $\bigcirc$ indicate experimental and corrected data, respectively. Optical setup conditions were (a) $Z_{\mathrm{i}}=435$ and $Z_{0}=2065$, (b) $Z_{\mathrm{i}}=200$ and $Z_{0}=2190 \mathrm{~mm}$.

Initial curves calculated by Eq. (1) were (a) $r_{0}=0.18-0.29$ and (b) $r_{0}=0.084-0.158 \mathrm{~mm}$.

ly. The initial curves calculated with Eq. (1) were $r_{0}$ $=0.18-0.29 \mathrm{~mm}$ in Fig. $5(\mathrm{a})$ and $r_{0}=0.08-0.16 \mathrm{~mm}$ in Fig. 5(b). According to these experimental results, $K_{\text {Icaustic }}$ was smaller than $K_{\text {Ia }}$ except the region where $r_{0}$, was very small, and this tendency became more pronounced with a smaller initial curve $r_{0}$.

As the initial curve $r_{0}$ decreases, the effect of three-dimensional stress is more evident around the crack tip, ${ }^{3), 5)}$ and the stress state surrounding the crack tip is merely a plane strain condition. Therefore, Eq. (1) can not be applied to determine the stress intensity factor, because it is based on a plane stress condition. The relation between the initial curve $r_{0}$ and $K_{\text {Icaustic }}$ is shown in Fig. 6 . The initial curve $r_{0}$ was then varied by changing the optical setup dimensions $Z_{0}$ and $Z_{\mathrm{i}}$ under the condition that $K_{\mathrm{Ia}}>3 \mathrm{MPa} \sqrt{\mathrm{m}}$. It is seen in Fig. 6 that $r_{0}$ is proportional to the ratio of $K_{\text {Icaustic }} / K_{\text {Ia }}$, and thus we obtain the following equation.

$$
K_{\text {Icaustic }} / K_{\text {Ia }}=2.94 r_{0}-0.14
$$

As mentioned above, the influence of the initial curve, $\gamma_{0}$, may be resulted from the deviation from a plane stress condition near the crack tip. However, the region influenced by $r_{0}$, was smaller than the data given in the literatures for notched specimens. ${ }^{4,5)}$ The stress intensity factors determined by the caustic method were corrected according to Eq. (2), and the results are given in Figs. 5(a) and (b). The corrected values agreed with the $K_{\text {Ia }}$ in the region of more than $3 \mathrm{MPa} \sqrt{\mathrm{m}}$. This indicated that the caustic method could be applied to determine the stress intensity factor of $\mathrm{Si}_{3} \mathrm{~N}_{4}$ in the region where the effect of the initial curve was corrected.

When the applied stress intensity factor $\left(K_{\mathrm{Ia}}\right)$ was less than $3 \mathrm{MPa} \sqrt{\mathrm{m}}$, the $K_{\text {Icaustic }}$ was greater than $K_{\text {Ia. }}$. Even though $K_{\text {Ia }}$ was zero, $K_{\text {Icaustic }}$ was not zero. This implies the existence of residual stress induced by the Vickers indentation used as the starter crack generator. Nishida et al. investigated the effect of residual stress caused by a Vickers indentation on fracture toughness as measured by a BI crack. ${ }^{8)} \mathrm{A}$ schematic diagram of a precrack introduced by the BI method is shown in Fig. 7. Residual stress is caused by the wedge effect of the plastic deforma-

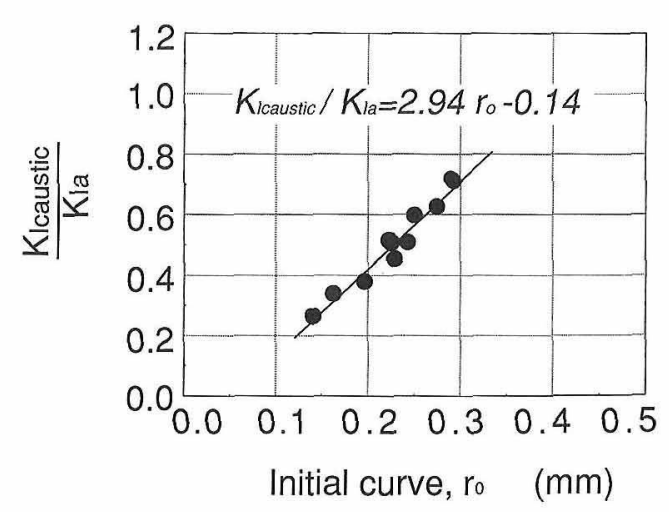

Fig. 6. Effect of initial curve, $r_{0}$, on $K_{\text {Icaustic. The initial curve } r_{0}}$ was varied by changing the optical setup dimensions $Z_{0}$ and $Z_{\mathrm{i}}$ un$\operatorname{der} K_{\mathrm{Ia}}>3 \mathrm{MPa} \sqrt{\mathrm{m}}$. 


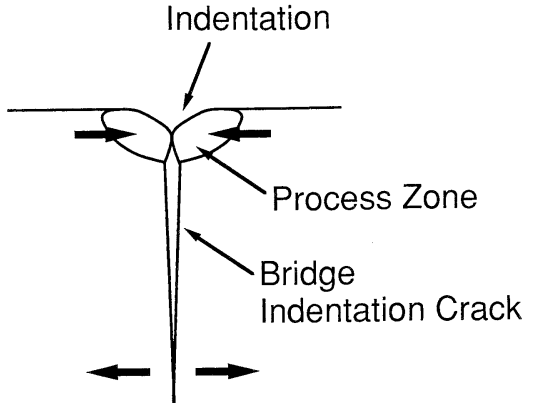

Fig. 7. Schematic diagram of Bridge Indentaion crack reported by Nishida et al. $^{8}$

tion zone induced by the Vickers indentation. Therefore, the residual stress intensity factor, $K_{\mathrm{IR}}$, decreases as the applied stress increases, because the wedge zone at the specimen surface becomes detached as a result of crack opening displacement.

In this experiment, the effect of residual stress was little in the region where the applied stress intensity factor $K_{\text {Ia }}$, was greater than $3 \mathrm{MPa} \sqrt{\mathrm{m}}$. A schematic diagram of stress intensity factor at crack tip $K_{\text {Itip }}\left(=K_{\text {Ia }}+K_{\mathrm{IR}}\right)$ is shown in Fig. 8. This model agrees with the experimental results, i.e., $K_{\text {IR }}$ should be inversely proportional to $K_{\text {Ia. }}$. Although the relation between $K_{\mathrm{IR}}$ and $K_{\mathrm{Ia}}$ was nonlinear as shown in Fig. 8, this was due to the elastic deformation of the wedge zone. The residual stress caused by a Vickers indentation is given by the following expression; ${ }^{9), 10)}$

$$
K_{\mathrm{IR}}=\chi_{\mathrm{r}} P / C^{3 / 2}
$$

where $\chi_{\mathrm{r}}$ is the constant, $P$ is the indentation load, and $C$ is the crack size. According to this relation, the residual stress should be released as an indentation crack is extended. However, the residual stress measured in the experiment was much larger than the expected value. This is thought to be the result not only of the wedge effect of the plastic deformation zone but also of the crack surface closure caused by the asperity contacts of crack surfaces.

In addition, one of the reasons why the region

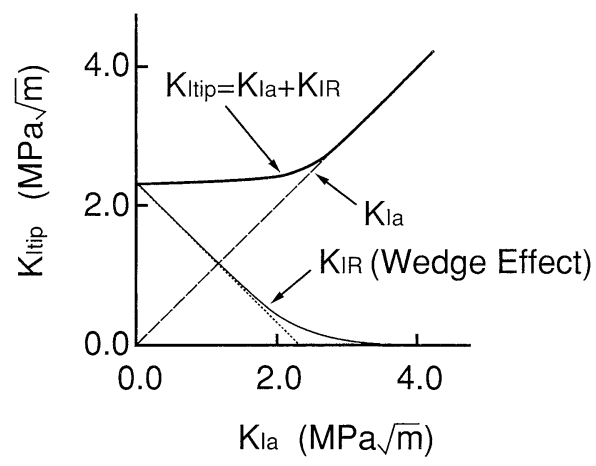

Fig. 8. Schematic diagram of residual stress intensity factor $\left(K_{\text {IR }}\right)$, applied stress intensity factor $\left(K_{\text {Ia }}\right)$ and crack tip stress intensity factor $\left(K_{\text {Itip }}\right)$. influenced by the initial curve, $r_{0}$ was smaller than the data given in the literatures ${ }^{4), 5}$ might be the effect of residual stress in $K_{\mathrm{Ia}}>3 \mathrm{MPa} \sqrt{\mathrm{m}}$. The influence of $r_{0}$ on $K_{\text {Icaustic }}$ is determined by the effects of three dimensional stress state and the residual stress at the crack tip. If the residual stress was not released completely in $K_{\mathrm{Ia}}>3 \mathrm{MPa} \sqrt{\mathrm{m}}$, the influence of the initial curve would be smaller than the literature data, i.e., the effect of raising the crack tip residual stress is to reduce the effect of three dimensional stress at crack tip.

\section{Conclusion}

The caustic method has many advantages for measuring the stress intensity factor, however, this is not easily applied to measuring the stress intensity factor for ceramics due to their low fracture toughness. In this study, the application of the caustic method to ceramics was investigated, and a technique was proposed for determining the stress intensity factor from a caustic image of a ceramics specimen. The degree of deviation of parallelism and surface roughness of a specimen are important factors in obtaining a clear caustic image of ceramics. A reliable method of measuring the diameter of a caustic image using the image processing proved effective in this experiment. The stress intensity factor of $\mathrm{Si}_{3} \mathrm{~N}_{4}$ with a BI (Bridge Indentation) crack was evaluated, and the residual stress intensity factor induced by a Vickers indentation as a starter crack generator was examined using this method.

The net stress intensity factor at a crack tip can be determined with this method, and so this method is expected to be applied to studies of the toughening mechanism of ceramics.

(This paper was presented at the Annual Meeting of the Ceramic Society of Japan, May 1990)

Acknowledgment The authors would like to thank Mr. H. Saito of the Scientific Research Laboratory at Nissan Motor Co. Ltd. for his assistance with the image processing.

\section{References}

1) J. F. Kalthoff, Int. J. Fracture, 27, 277-98 (1985).

2) P. S. Theocaris, Appl. Opt., 10, 2240-47 (1971).

3) K. Shimizu and H. Shimada, J. Japan Soc. for Nondestructive Inspection, 27, 399-407 (1978).

4) K. Shimizu, K. Otani and S. Takahashi, Proc. 9th Int. Conference on Experimental Mechanics, Copenhagen, Denmark (1990) pp. 1462-71.

5) K. Shimizu, S. Takahashi and H. Shimada, Experimental Mechanics, 25, 154-60 (1985).

6) K. Shimizu and S. Takahashi, Optics and Lasers in Engineering, 13, 251-77 (1990).

7) T. Nose and T. Fujii, J. Am. Ceram. Soc., 71, 328-33 (1988).

8) T. Nishida, T. Shiono, A. Nagai and T. Nishikawa, Seramikkusu Ronbunshi (J. Ceram. Soc. Japan), 97, 715-20 (1989).

9) D. B. Marshall and B. R. Lawn, J. Mater. Sci.,14, 2001-12 (1979).

10) D. B. Marshall, B. R. Lawn and P. Chantikul, J. Mater. Sci., 14, 2225-35 (1979). 